\title{
Arterial Stiffness Measured Via Carotid Femoral Pulse Wave Velocity Is Associated With Disease Severity in COPD
}

\author{
Halit Cinarka MD, Servet Kayhan MD, Aziz Gumus MD, Murtaza Emre Durakoglugil MD, \\ Turan Erdogan MD, Ibrahim Ezberci MD, Asiye Yavuz MD, Sevket Ozkaya MD, \\ and Unal Sahin MD
}

\begin{abstract}
BACKGROUND: Patients with COPD face an increased risk of cardiovascular disease and increased cardiac mortality. Carotid femoral pulse wave velocity (cf-PWV) is a validated measure of arterial stiffness, a well recognized predictor of adverse cardiovascular outcomes, and offers higher predictive value than classical cardiovascular risk factors. We investigated the association between COPD and arterial stiffness using cf-PWV as a noninvasive technique. METHODS: This clinical study was prospective, observational, and cross-sectional. Sixty-two subjects with stable COPD and 22 healthy controls underwent physical examination, chest x-rays, pulmonary function tests, arterial blood gas analysis, and 6-min walk test, and cf-PWV was measured via a validated tonometry system. RESULTS: The COPD subjects had greater arterial stiffness than the control subjects, and that difference was associated with lower $\mathrm{FEV}_{1}, \mathrm{P}_{\mathrm{aO}}$, and oxygen saturation during the 6-min walk test. We observed higher cf-PWV in the COPD subjects with severe COPD than in the subjects with mild to moderate COPD. Only FEV $\mathrm{F}_{1}$ was an independent predictor of cf-PWV. CONCLUSIONS: Our results suggest that arterial stiffness is increased in subjects with more severe and advanced COPD than in those with mild to moderate COPD. Air flow limitation and hypoxemia may induce increased arterial stiffness in COPD patients. Key words: cardiovascular disease; clinical respiratory medicine; COPD; inflammation; respiratory function test. [Respir Care 2014;59(2):274-280. (C) 2014 Daedalus Enterprises]
\end{abstract}

\section{Introduction}

Patients with COPD face an increased risk of cardiovascular disease, as compared to the normal population; moreover, cardiac disease is among the leading causes of death in COPD patients. ${ }^{1-3}$ COPD is associated with sys-

Drs Cinarka, Kayhan, Gumus, Yavuz, Ozkaya, and Sahin are affiliated with the Department of Pulmonary Medicine, Drs Durakoglugil and Erdogan are affiliated with the Department of Cardiology, and Dr Ezberci is affiliated with the Department of Family Medicine, Recep Tayyip Erdogan University, Rize, Turkey.

The authors have disclosed no conflicts of interest.

Correspondence: Servet Kayhan MD, Department of Pulmonary Medicine, Recep Tayyip Erdogan University, Rize, Turkey. E-mail: kayhan servet@gmail.com.

DOI: $10.4187 /$ respcare.02621 temic inflammation, which can initiate comorbidities. ${ }^{1,4}$ Additionally, air-flow obstruction profoundly affects cardiac function and gas exchange, leading to systemic consequences. An increased prevalence of ischemic heart disease and hypertension is seen in COPD patients, and these conditions are linked to poor prognoses. ${ }^{3}$

Carotid-femoral pulse wave velocity (cf-PWV) is the gold standard measurement for arterial stiffness. ${ }^{5-7}$ Previous studies have documented the importance of arterial stiffness as a prognostic factor and an independent predictor of all-cause and cardiovascular mortality. ${ }^{1}$ Arterial stiffness is a well known predictor of cardiovascular risk and can be assessed via radial artery tonometry, aortic PWV, or cf-PWV. ${ }^{8}$

As a response to the systemic inflammation associated with COPD, arterial stiffness and cardiovascular risk may also increase in this disease. ${ }^{9}$ Due to this increased systemic inflammation and impaired endothelial nitric oxide production, COPD patients also frequently exhibit endothelial dysfunction. ${ }^{10}$ The aim of our study was to deter- 


\section{Arterial Stiffness Measured Via Carotid Femoral Pulse Wave Velocity}

mine the relationship between arterial stiffness and airflow limitation in patients with COPD.

\section{Methods}

This was a prospective, observational, descriptive study approved by the ethics committee of Recep Tayyip Erdogan University, and designed and conducted in accordance with the Declaration of Helsinki, between September 1, 2012, and December 31, 2012, in our pulmonology clinic. All subjects gave informed consent.

\section{Subjects}

We recruited 62 consecutive patients with stable COPD and 22 healthy subjects. We excluded COPD patients with history of any cardiovascular disease, hypertension, or diabetes mellitus. All subjects were examined physically by a cardiologist. Electrocardiographic and echocardiographic examinations were also performed to rule out any cardiac disease. Physical examinations, chest $\mathrm{x}$ rays, pulmonary function tests, arterial blood gas analysis, and 6-min walk test were performed with each subject. We measured C-reactive protein as a marker of systemic inflammation. The spirometric classification of COPD was per the Global Initiative for Chronic Obstructive Lung Disease $^{11}$ (GOLD):

Stage 1: $\mathrm{FEV}_{1}>80 \%$ of predicted

Stage 2: $\mathrm{FEV}_{1} 50-80 \%$ of predicted

Stage 3: FEV $130-50 \%$ of predicted

Stage 4: $\mathrm{FEV}_{1}<30 \%$ of predicted

\section{Pulmonary Function Tests}

Pulmonary function tests were conducted with a spirometer (nSpire Health, Longmont, Colorado), with the subject sitting, and the spirometry maneuver was repeated at least 3 times. The best results were retained for analysis. The percent-of-predicted values were calculated from the European Respiratory Society's standards data. ${ }^{12}$

\section{COPD Exacerbations}

All the COPD subjects were asked about the number of COPD exacerbations (ie, sustained and acute symptoms worsening from the stable state, and that required additional treatment $)^{13}$ they had had in the past 1 year.

\section{Arterial Blood Gas Analysis}

From the COPD subjects, arterial blood samples were taken from the radial artery while the subject was breathing room air and had been at rest for $15 \mathrm{~min}$. Blood gas analysis (RapidLab 248/348, Siemens Healthcare, Berlin,

\section{QUICK LOOK}

\section{Current knowledge}

Patients with COPD have an increased risk of cardiovascular disease and mortality. Carotid femoral pulse wave velocity is a well recognized predictor of adverse cardiovascular outcomes, with a higher predictive value than classic cardiovascular risk factors.

\section{What this paper contributes to our knowledge}

Patients with severe COPD had higher pulse wave velocity, which suggests increased arterial stiffness, compared to patients with mild and moderate COPD. Hypoxemia in severe COPD may increase arterial stiffness.

Germany) was performed immediately. We did not perform arterial blood gas analysis in the control subjects. We measured oxygen saturation in the control subjects with pulse oximetry (3303, BCI International/Smiths Medical, St Paul, Minnesota). We excluded any healthy individuals whose $\mathrm{S}_{\mathrm{pO}_{2}}$ was $\leq 95 \%$.

\section{6-Minute Walk Test}

The 6-min walk test was performed in our pulmonology clinic, in a 30-m corridor, and per American Thoracic Society guidelines. ${ }^{14} \mathrm{We}$ measured pulse rate and systolic and diastolic blood pressure before and after the test. Before, during, and after the test we measured $\mathrm{S}_{\mathrm{pO}_{2}}$ (MD300C12, ChoiceMMed, Beijing, China) and recorded the lowest and the highest $\mathrm{S}_{\mathrm{pO}_{2}}$. During the test, an $\mathrm{S}_{\mathrm{pO}_{2}}$ decrease of $\geq 4 \%$ from the subject's baseline $\mathrm{S}_{\mathrm{pO}_{2}}$ was considered desaturation.

\section{Pulse Wave Velocity}

An experienced cardiologist, who was blinded to patient data, performed cf-PWV assessments, in the morning after an overnight fast (ie, $\geq 8 \mathrm{~h}$ ) from food and cigarettes. The cf-PWV was measured with a validated noninvasive device (SphygmoCor, AtCor Medical, Sydney, Australia), from the pulse transmit time between 2 measurement sites. The distance traveled by the pulse wave over the surface of the body was measured with a tape measure, from the sternal notch to the right carotid artery, and from the sternal notch to the right femoral artery, and was divided by the transit time. The expert consensus document on arterial stiffness methodological issues and clinical applications advises on cf-PWV measurement procedures, and provides arguments for the use of $80 \%$ of the direct carotid-femoral 


\begin{tabular}{|c|c|c|c|c|c|c|}
\hline & \multicolumn{2}{|c|}{ COPD Subjects } & \multirow[b]{2}{*}{$\begin{array}{l}\text { Healthy } \\
\text { Control } \\
\text { Subjects } \\
(n=22)\end{array}$} & \multicolumn{3}{|c|}{$P$} \\
\hline & $\begin{array}{c}\text { GOLD } \\
\text { Stage } 1 \text { or } 2 \\
(n=32)\end{array}$ & $\begin{array}{c}\text { GOLD } \\
\text { Stage } 3 \text { or } 4 \\
(n=30)\end{array}$ & & $\begin{array}{c}\text { GOLD } \\
\text { Stage } 1 \text { or } 2 \\
\text { vs GOLD } \\
\text { Stage } 3 \text { or } 4\end{array}$ & $\begin{array}{c}\text { GOLD } \\
\text { Stage } 1 \text { or } 2 \\
\text { vs Healthy } \\
\text { Controls }\end{array}$ & $\begin{array}{c}\text { GOLD } \\
\text { Stage } 3 \text { or } 4 \\
\text { vs Healthy } \\
\text { Controls }\end{array}$ \\
\hline Male/female, no. & $1 / 31$ & $1 / 29$ & $1 / 21$ & & & \\
\hline Age, y & $59.2 \pm 10.2$ & $65.2 \pm 8.6$ & $57.4 \pm 7.6$ & .03 & .74 & .008 \\
\hline Body mass index, $\mathrm{kg} / \mathrm{m}^{2}$ & $27.2 \pm 5.9$ & $26.8 \pm 5.4$ & $26.7 \pm 3.0$ & .93 & .93 & .99 \\
\hline Smoking history, pack-years & $33.2 \pm 11.8$ & $41.6 \pm 10.9$ & $31.1 \pm 12.6$ & .02 & .79 & .006 \\
\hline Pulse wave velocity, $\mathrm{m} / \mathrm{s}$ & $9.9 \pm 3.3$ & $12.7 \pm 3.9$ & $7.32 \pm 1.88$ & .004 & .01 & $<.001$ \\
\hline
\end{tabular}

distance as the most accurate distance estimate. ${ }^{15}$ We used the following formula for the cf-PWV measurements:

Estimated direct distance $=[(0.45 \times$ subtracted distance $)$

$$
+(0.21 \times \text { height })+0.08] \times 0.8
$$

\section{Statistical Analysis}

We used statistics software (SPSS 15, SPSS, Chicago, Illinois) to analyze the data. Continuous variables are presented as mean $\pm \mathrm{SD}$. Categorical variables are expressed as number and percent. The Kolmogorov-Smirnov test was used to analyze normally distributed data. The MannWhitney U test and the Kruskal-Wallis test were used for nonparametric data. Logistic regression was used for the multivariate analysis of the independent variables. The Student $t$ test and analysis of variance were used to compare the averages of the parametric variables. $P<.05$ was considered statistically significant.

\section{Results}

The study group included 32 subjects with $\mathrm{FEV}_{1} \geq 50 \%$ of predicted (GOLD stages 1 and 2) and 30 subjects with $\mathrm{FEV}_{1}<50 \%$ of predicted (GOLD stages 3 and 4) (Table 1). Our subjects were mainly male, and the COPD subjects were older than the controls. The COPD subjects with $\mathrm{FEV}_{1} \geq 50 \%$ of predicted had smoking habits similar to the controls, but the COPD subjects with $\mathrm{FEV}_{1}<50 \%$ of predicted had more intense smoking history than the controls or the COPD subjects with $\mathrm{FEV}_{1} \geq 50 \%$ of predicted. We found higher cf-PWV in both the COPD subject groups than in the healthy controls, and the subjects with $\mathrm{FEV}_{1}<50 \%$ of predicted had higher mean cf-PWV than the subjects with $\mathrm{FEV}_{1} \geq 50 \%$ of predicted.

Table 2 shows the results for the COPD subjects. The mean 6-min walk distance was $360 \pm 69 \mathrm{~m}$ in the COPD subjects and $427 \pm 64 \mathrm{~m}$ in the control group. As expected the blood gas values, pulmonary function test results, and 6-min walk test parameters were significantly worse in the GOLD stage 3 and 4 subjects than in the GOLD stage 1 and 2 subjects. The cf-PWV values in the COPD subjects were independent of age and body mass index in the univariate analysis of covariance, and cf-PWV increased with COPD severity $(P=.02)$.

The mean cf-PWV was significantly $(P=.003)$ higher in the COPD subjects $(10.95 \pm 3.74 \mathrm{~m} / \mathrm{s}, n=62)$ than in the controls $(7.32 \pm 1.88 \mathrm{~m} / \mathrm{s}, n=22)$. Table 3 shows the Pearson correlation coefficients between cf-PWV and the physiologic variables. cf-PWV weakly correlated with age $(P=.049)$, but did not correlate with smoking history or body mass index. We found weak correlations between cf-PWV and $\mathrm{P}_{\mathrm{aO}_{2}}(P=.007, \mathrm{r}=-0.341)$ (Fig. 1), $\mathrm{FEV}_{1}$ $(P=.001, \mathrm{r}=-0.408)($ Fig. 2$)$, and FVC $(P=.008$, $\mathrm{r}=-0.333)$, and a moderate correlation with $\mathrm{FEF}_{25-75}$ $(P<.001, \mathrm{r}=-0.511)$. We did not find a correlation between cf-PWV and serum $\mathrm{C}$-reactive protein $(P=.83$, $\mathrm{r}=0.03)$ or smoking history $(P=.43, \mathrm{r}=0.10)$.

We observed higher cf-PWV in the COPD subjects with severe COPD than in the subjects with mild to moderate COPD. The linear regression analysis found that only $\mathrm{FEV}_{1}$ was an independent predictor of cf-PWV $(P=.043)$. Mean cf-PWV was nonsignificantly $(P=.33)$ higher in the subjects who had one or more exacerbations in the last 1 year $(12.23 \pm 4.09 \mathrm{~m} / \mathrm{s}, n=14)$ than in the subjects who had not had an exacerbation in the past year $(11.01 \pm 3.81 \mathrm{~m} / \mathrm{s}, n=48)$.

\section{Discussion}

Arterial stiffness is mainly associated with aging and hypertension, and it indicates structural and functional changes within the arterial wall. ${ }^{16,17}$ cf-PWV is an independent predictor of mortality and stroke in the general population and in patients with end-stage renal disease, 


\section{Arterial Stiffness Measured Via Carotid Femoral Pulse Wave Velocity}

Table 2. Results for the COPD Subjects

\begin{tabular}{|c|c|c|c|}
\hline & $\begin{array}{c}\text { GOLD } \\
\text { Stage } 1 \text { or } 2 \\
(n=32)\end{array}$ & $\begin{array}{c}\text { GOLD } \\
\text { Stage } 3 \text { or } 4 \\
(n=30)\end{array}$ & $P$ \\
\hline $\mathrm{pH}$ & $7.41 \pm 0.03$ & $7.40 \pm 0.02$ & .55 \\
\hline $\mathrm{P}_{\mathrm{aO}_{2}}, \mathrm{~mm} \mathrm{Hg}$ & $77.1 \pm 7.0$ & $67.2 \pm 7.5$ & $<.001$ \\
\hline $\mathrm{P}_{\mathrm{aCO}_{2}}, \mathrm{~mm} \mathrm{Hg}$ & $38.3 \pm 2.9$ & $40.7 \pm 5.1$ & .03 \\
\hline $\mathrm{S}_{\mathrm{aO}_{2}}$ & $96.4 \pm 1.3$ & $94.2 \pm 2.2$ & $<.001$ \\
\hline $\mathrm{FEV}_{1}, \%$ predicted & $64 \pm 9$ & $38 \pm 8$ & $<.001$ \\
\hline FVC, $\%$ predicted & $83 \pm 11$ & $55 \pm 11$ & $<.001$ \\
\hline $\mathrm{FEV}_{1} / \mathrm{FVC}$ & $61 \pm 4$ & $54 \pm 7$ & $<.001$ \\
\hline $\mathrm{FEF}_{25-75}, \%$ predicted & $36 \pm 10$ & $20 \pm 8$ & $<.001$ \\
\hline Peak expiratory flow, $\%$ predicted & $54 \pm 13$ & $38 \pm 12$ & $<.001$ \\
\hline 6-min-walk distance, $\mathrm{m}$ & $427 \pm 64$ & $360 \pm 69$ & $<.001$ \\
\hline Highest $\mathrm{S}_{\mathrm{aO}_{2}}, \%$ & $97.4 \pm 0.9$ & $95.2 \pm 2.4$ & $<.001$ \\
\hline Lowest $\mathrm{S}_{\mathrm{aO}_{2}}, \%$ & $94.4 \pm 3.3$ & $90.3 \pm 5.2$ & .001 \\
\hline Decrease in $\mathrm{S}_{\mathrm{aO}_{2}}$ & $3.1 \pm 3.2$ & $4.9 \pm 3.6$ & .03 \\
\hline $\begin{array}{l}\text { Values are mean } \pm \mathrm{SD} \text {. } \\
\mathrm{S}_{\mathrm{aO}_{2}}=\text { oxygen saturation measured from an an } \\
\mathrm{FEF}_{25-75}=\text { forced expiratory flow during the }\end{array}$ & & & \\
\hline
\end{tabular}

Table 3. Pearson Correlation Analysis for Carotid-Femoral Artery Pulse Wave Velocity and Physiologic Variables in Subjects With COPD

\begin{tabular}{|c|c|c|}
\hline & \multicolumn{2}{|c|}{$\begin{array}{c}\text { Pearson Correlation } \\
\text { With Pulse Wave } \\
\text { Velocity }\end{array}$} \\
\hline & $\mathrm{r}$ & $P$ \\
\hline Age & 0.25 & .049 \\
\hline Smoking history & 0.10 & .43 \\
\hline Body mass index & 0.08 & .54 \\
\hline Percent-of-predicted $\mathrm{FEV}_{1}$ & -0.41 & .001 \\
\hline Percent-of-predicted FVC & -0.33 & .008 \\
\hline Percent-of-predicted $\mathrm{FEF}_{25-75}$ & -0.51 & $<.001$ \\
\hline Percent-of-predicted peak expiratory flow & -0.23 & .08 \\
\hline $\mathrm{pH}$ & -0.01 & .93 \\
\hline $\mathrm{P}_{\mathrm{aO}_{2}}$ & -0.34 & .007 \\
\hline $\mathrm{P}_{\mathrm{aCO}_{2}}$ & 0.15 & .25 \\
\hline Arterial oxygen saturation & -0.28 & .03 \\
\hline 6-min-walk distance & -0.36 & .004 \\
\hline Decrease in $\mathrm{S}_{\mathrm{aO}_{2}}$ & 0.44 & $<.001$ \\
\hline
\end{tabular}

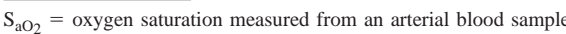

hypertension, and diabetes. ${ }^{8,18-20}$ Therefore, European guidelines on cardiovascular disease prevention consider cf-PWV a test of target organ damage in hypertensive patients. $^{21,22}$ In a cohort consisting primarily of treated hypertensive subjects, aortic PWV was associated with target organ damage in coronary, cerebral, and peripheral arterial beds. ${ }^{22}$ cf-PWV is a surrogate marker for vascular stiffness. ${ }^{15}$ The present study was conducted to investigate the relationship of air-flow limitation and hypoxemia to

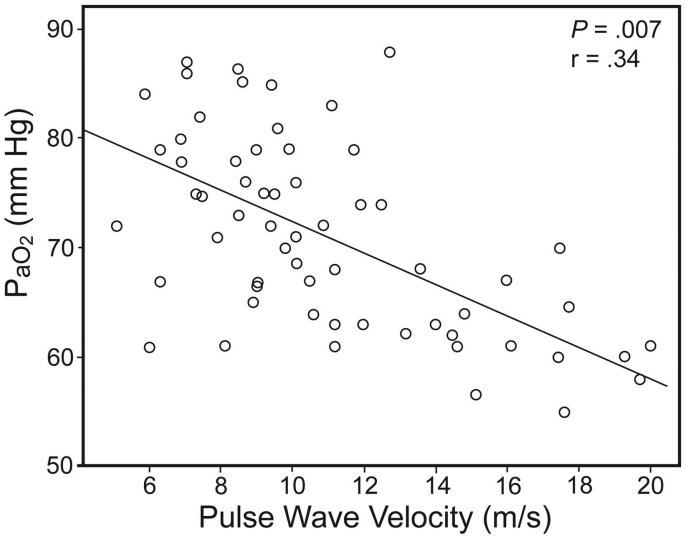

Fig. 1. Carotid-femoral pulse wave velocity versus $\mathrm{P}_{\mathrm{aO}_{2}}$.

cf-PWV in subjects with COPD; interestingly, an increased cf-PWV was indeed observed in COPD subjects, and a decline in pulmonary function test results and $\mathrm{P}_{\mathrm{aO}_{2}}$ was associated with higher cf-PWV.

Measure of arterial stiffness has been used to predict adverse cardiovascular events in different populations. ${ }^{3,5,23,24}$ A recent meta-analysis that included individuals at high and low risk of cardiovascular events showed that elevated aortic PWV was associated with an increased risk of adverse cardiovascular events and cardiovascular and all-cause mortality. ${ }^{24}$ In the offspring cohort of the Framingham Heart Study, aortic PWV was independently associated with cardiovascular events. ${ }^{5}$ Similarly, Terai et $\mathrm{al}^{23}$ found that aortic PWV predicted myocardial infarction or stroke in a cohort of 676 subjects with essential hypertension, during a mean follow-up of 57 months. 


\section{Arterial Stiffness Measured Via Carotid Femoral Pulse Wave Velocity}

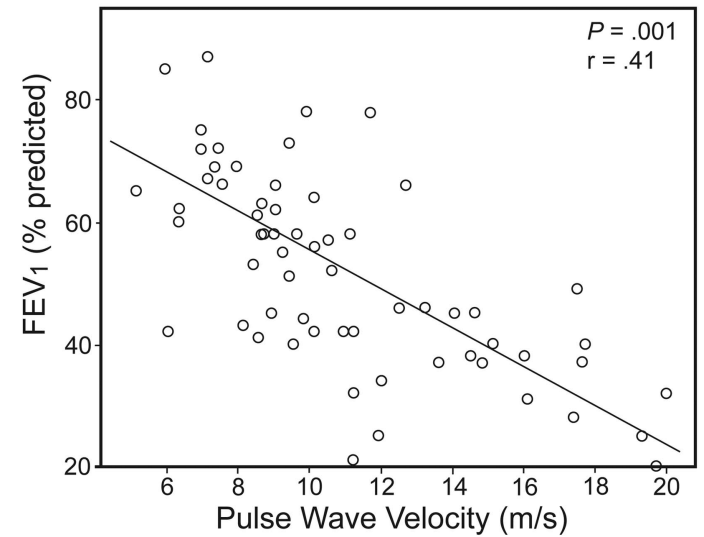

Fig. 2. Carotid-femoral pulse wave velocity versus FEV I. $_{1}$

COPD and coronary artery disease are both highly prevalent worldwide, and they share common risk factors, including cigarette smoking, advanced age, and sedentary lifestyle. It is well documented that patients with severe and very severe forms of COPD have a greater risk of cardiovascular disease. ${ }^{25}$ Patients with severe air-flow limitations have a significantly higher risk of death from coronary artery disease, and this higher risk is independent of smoking behavior, age, and sex ${ }^{26}$ In the Lung Health Trial, approximately 6,000 patients were followed for 14 years, and $\mathrm{FEV}_{1}$ was found to be an independent predictor of the probability of mortality from myocardial infarction. ${ }^{27}$ Our study reveals that arterial stiffness increases with COPD severity, which could explain why the risk of myocardial infarction is higher for COPD patients. Indeed, arterial stiffness as a result of vascular disease is a good predictor of cardiovascular events, and can be assessed noninvasively by measuring cf-PWV. ${ }^{8}$ Age, smoking history, body mass index, pulmonary function test results, and arterial blood gas values may affect cf-PWV. Our subjects included COPD patients who smoked more heavily than our control group, but cf-PWV did not correlate with smoking history. There was a weak correlation between age and cf-PWV $(P=.049, \mathrm{r}=0.25)$, but no correlation between body mass index and cf-PWV.

Another study ${ }^{28}$ also found that arterial stiffness is increased in patients with COPD, as compared to normal smokers and non-smokers; however, those authors found that arterial stiffness was unrelated to COPD severity measured by circulating C-reactive protein concentration, which is not in accordance with our findings based on spirometry results. Sabit et $\mathrm{al}^{29}$ included patients with stable COPD (GOLD stages 1 through 4), and healthy smokers and ex-smokers were used as control subjects. They observed greater mean aortic PWV in the COPD subjects than in the control subjects. Furthermore, much like our results, aortic PWV correlated with GOLD stage: more severe air-flow limitation was associated with higher cf-
PWV. ${ }^{28-30}$ Ultimately, COPD and hypoxemia may increase arterial stiffness, which may promote thickening of arterial walls, atherosclerotic plaque formation, and vascular remodeling. The sequences of this process may start in the early stages of COPD and worsen with the decline in lung function.

We thought that the systemic inflammation related to smoking may increase arterial stiffness in COPD patients. To determine the association between the systemic inflammation and smoking, we measured serum C-reactive protein in the COPD subjects, but found no significant correlation between these parameters. Confounders other than systemic inflammation, such as impaired microcirculation related to hypoxemia and increased local inflammatory reactions related to smoking in target organs (lungs, heart and arteries), may cause arterial stiffness.

The systemic inflammation in COPD has been implicated in the pathogenesis of cardiovascular comorbidities such as ischemic heart disease and atherosclerosis. ${ }^{31}$ The number of macrophages and interferon-c secreting Th1 lymphocytes increase in atherosclerotic plaques as well as in the peripheral lung regions in COPD patients. ${ }^{32,33}$ The increased arterial stiffness may predispose to systemic hypertension and an increased risk of cardiovascular disease in COPD patients. ${ }^{31}$ At the same time, arterial stiffness may reflect some pathological mechanisms, such as systemic inflammation, connective tissue abnormalities, impairment in endothelial function, and impairment of nitric oxide production, that are associated with the pathogenesis of COPD. ${ }^{10}$ These results might lead to the conclusion that arterial stiffness increases in the latter stages of COPD.

Castagna et al assessed the prevalence of peripheral arterial disease and its implications for exercise limitation in COPD patients. ${ }^{34}$ They stated that there is a considerable effect of peripheral arterial disease on exercise intolerance, and it should be taken into account in COPD treatments, including pulmonary rehabilitation programs.

Smoking-induced systemic inflammation may cause an inflammatory response resulting in damage in several organs and structures. The repair of the damage in the lungs triggered by smoking and noxious gases results in COPD, while the repair of the damage in systemic arteries results in atherosclerosis and increased arterial stiffness. Severe inflammatory reactions and pathologic structural changes occur in the lungs and the vessels, particularly in genetically predisposed individuals. And this link may explain why COPD and arterial stiffness did not exist in all of the smokers. To explain how arterial stiffness occurs in other groups of patients who do not have COPD or hypoxemia and are non-smokers, some other factors also should be detected. Risk factors other than smoking that play an important role in the mechanism of arterial stiffness include obesity, diabetes mellitus, age, sex, hyperlipidemia, 


\section{Arterial Stiffness Measured Via Carotid Femoral Pulse Wave Velocity}

lifestyle, and genetic factors. As a result, to implicate COPD as a cause of atherosclerosis, more elaborate investigations are required.

Our study has several limitations. First, a cascade of events starting with hypoxemia and leading to arterial stiffness in smoking-associated COPD concomitant with air-flow limitation could not be clarified. Second, the association between arterial stiffness and the other states of chronic airway obstruction with airway limitation and hypoxemia, such as alpha-1 antitrypsin deficiency, bullous emphysema, and chronic persistent asthma, could not be investigated in the absence of cardiovascular disease. Third, other confounders, such as impaired microcirculation and increased local inflammation, could not be identified. Fourth, the main limitation of this study is the small sample size. Fifth, our study is cross-sectional in nature, so our results cannot be used to implicate causality. Despite these limitations, we used validated end points to strengthen our results.

\section{Conclusions}

We believe that hypoxemia affects arterial stiffness, and vice versa, in a vicious cycle, and can lead to more rapid clinical deterioration. Moreover, cf-PWV is increased in COPD patients, and arterial stiffness is more prominent in patients with severe COPD than in patients with mild to moderate COPD.

\section{REFERENCES}

1. Barnes PJ, Celli BR. Systemic manifestations and comorbidities of COPD. Eur Respir J 2009;33(5):1165-1185.

2. Johnston AK, Mannino DM, Hagan GW, Davis KJ, Kiri VA. Relationship between lung function impairment and incidence or recurrence of cardiovascular events in a middle-aged cohort. Thorax 2008; 63(7):599-605.

3. Lange P, Mogelvang R, Marott JL, Vestbo J, Jensen JS. Cardiovascular morbidity in COPD: A study of the general population. COPD 2010;7(1):5-10

4. Gumus A, Kayhan S, Cinarka H, Kirbas A, Bulmus N, Yavuz A, et al. High serum YKL-40 level in patients with COPD is related to hypoxemia and disease severity. Tohoku J Exp Med 2013;229(2): 163-170.

5. Mitchell GF, Hwang SJ, Vasan RS, Larson MG, Pencina MJ, Hamburg NM, et al. Arterial stiffness and cardiovascular events: the Framingham Heart Study. Circulation 2010;121(4):505-511.

6. Van Bortel LM, Laurent S, Boutouyrie P, Chowienczyk P, Cruickshank JK, De Backer T, et al; Artery Society; European Society of Hypertension Working Group on Vascular Structure and Function; European Network for Noninvasive Investigation of Large Arteries. Expert consensus document on the measurement of aortic stiffness in daily practice using carotid - femoral pulse wave velocity. J Hypertens 2012;30(3):445-448.

7. Reference Values for Arterial Stiffness' Collaboration. Determinants of pulse wave velocity in healthy people and in the presence of cardiovascular risk factors: 'establishing normal and reference values’. Eur Heart J 2010;31(19):2338-2350.
8. Mattace-Raso FU, van der Cammen TJ, Hofman A, van Popele NM, Bos ML, Schalekamp MA, et al. Arterial stiffness and risk of coronary heart disease and stroke: The Rotterdam Study. Circulation 2006;113(5):657-663.

9. Mills NL, Miller JJ, Anand A, Robinson SD, Frazer GA, Anderson $\mathrm{D}$, et al. Increased arterial stiffness in patients with chronic obstructive pulmonary disease: a mechanism for increased cardiovascular risk. Thorax 2008;63(4):306-311.

10. Barr RG, Mesia-Vela S, Austin JH, Basner RC, Keller BM, Reeves $\mathrm{AP}$, et al. Impaired flow mediated dilation is associated with low pulmonary function and emphysema in ex-smokers: the Emphysema and Cancer Action Project (EMCAP) Study. Am J Respir Crit Care Med 2007;176(12):1200-1207.

11. Global Initiative for Chronic Obstructive Lung Disease (GOLD). Global strategy for the diagnosis, management, and prevention of chronic obstructive pulmonary disease, revised 2011. http://www.gold copd.org/guidelines-global-strategy-for-diagnosis-management.html. Accessed November 27, 2013.

12. Quanjer PH, Tammeling GJ, Cotes JE, Pedersen OF, Peslin R, Yernault JC. Lung volumes and forced ventilatory flows. Standardized lung function testing. Official statement of the European Respiratory Society. Eur Respir J 1993;6(Suppl 16):5-40.

13. Burge S, Wedzicha JA. COPD exacerbations: definitions and classifications. Eur Respir J Suppl 2003;41(1):46S-53S.

14. Committee on Proficiency Standards for Clinical Pulmonary Function Laboratories. ATS statement: guidelines for the six-minute walk test. Am J Respir Crit Care Med 2002;166(1):111-117.

15. Laurent S, Cockcroft J, Van Bortel L, Boutouyrie P, Giannattasio C, Hayoz D, et al; European Network for Noninvasive Investigation of Large Arteries. Expert consensus document on arterial stiffness: Methodological issues and clinical applications. Eur Heart J 2006;27(21): 2588-2605.

16. Redheuil A, Yu WC, Wu CO, Mousseaux E, de Cesare A, Yan R, et al. Reduced ascending aortic strain and distensibility: earliest manifestations of vascular aging in humans. Hypertension 2010;55(2): 319-326.

17. Cecelja M, Chowienczyk P. Dissociation of aortic pulse wave velocity with risk factors for cardiovascular disease other than hypertension: a systematic review. Hypertension 2009;54(6):1328-1336.

18. Shoji T, Emoto M, Shinohara K, Kakiya R, Tsujimoto Y, Kishimoto $\mathrm{H}$, et al. Diabetes mellitus, aortic stiffness, and cardiovascular mortality in end-stage renal disease. J Am Soc Nephrol 2001;12(10): 2117-2124.

19. Laurent S, Boutouyrie P, Asmar R, Gautier I, Laloux B, Guize L, et al. Aortic stiffness is an independent predictor of all-cause and cardiovascular mortality in hypertensive patients. Hypertension 2001; 37(5):1236-1241.

20. Cicek Y, Durakoglugil ME, Kocaman SA, Cetin M, Erdogan T, Dogan S, et al. Non-dipping pattern in untreated hypertensive patients is related to increased pulse wave velocity independent of raised nocturnal blood pressure. Blood Press 2013;2(1):34-38.

21. Coutinho T, Turner ST, Kullo IJ. Aortic pulse wave velocity is associated with measures of subclinical target organ damage. JACC Cardiovasc Imaging 2011;4(7):754-761.

22. Graham I, Atar D, Borch-Johnsen K, Boysen G, Burell G, Cifkova $\mathrm{R}$, et al. European guidelines on cardiovascular disease prevention in clinical practice: Full text. Fourth Joint Task Force of the European Society of Cardiology and other societies on cardiovascular disease prevention in clinical practice. Eur J Cardiovasc Prev Rehabil 2007; 14(Suppl 2):S1-S113.

23. Terai M, Ohishi M, Ito $\mathrm{N}$, Takagi $\mathrm{T}$, Tatara $\mathrm{Y}$, Kaibe $\mathrm{M}$, et al. Comparison of arterial functional evaluations as a predictor of cardiovascular events in hypertensive patients: the Non-Invasive Ath- 


\section{Arterial Stiffness Measured Via Carotid Femoral Pulse Wave Velocity}

erosclerotic Evaluation in Hypertension (NOAH) study. Hypertens Res 2008;31(6):1135-1145.

24. Vlachopoulos C, Aznaouridis K, Stefanadis C. Prediction of cardiovascular events and all-cause mortality with arterial stiffness: a systematic review and meta-analysis. J Am Coll Cardiol 2010;55(13): 1318-1327.

25. Mannino DM, Thorn D, Swensen A, Holguin F. Prevalence and outcomes of diabetes, hypertension, and cardiovascular disease in chronic obstructive pulmonary disease. Eur Respir J 2008;32(4):962-969.

26. Brekke PH, Omland T, Smith P, Soyseth V. Underdiagnosis of myocardial infarction in COPD-Cardiac Infarction Injury Score (CIIS) in patients hospitalised for COPD exacerbation. Respir Med 2008; 102(9):1243-1347.

27. Anthonisen NR, Skeans MA, Wise RA, Manfreda J, Kanner RE, Connett JE. The effects of a smoking cessation intervention on 14.5year mortality: a randomized clinical trial. Ann Intern Med 2005; 142(4):233-239.

28. McAllister DA, Maclay JD, Mills NL, Mair G, Miller J, Anderson D, et al. Arterial stiffness is independently associated with emphysema severity in patients with chronic obstructive pulmonary disease. Am J Respir Crit Care Med 2007;176(12):1208-1214.
29. Sabit R, Bolton CE, Edwards PH, Pettit RJ, Evans WD, McEniery $\mathrm{CM}$, et al. Arterial stiffness and osteoporosis in chronic obstructive pulmonary disease. Am J Respir Crit Care Med 2007;175(12): 1259-1265.

30. Albu A, Fodor D, Bondor C, Suciu O. Carotid arterial stiffness in patients with chronic obstructive pulmonary disease. Acta Physiol Hung 2011;98(2):117-127.

31. Agusti A, Soriano JB. COPD as a systemic disease. COPD 2008; 5(2):133-138.

32. Yan ZQ, Hansson GK. Innate immunity, macrophage activation, and atherosclerosis. Immunol Rev 2007;219(1):187-203.

33. Frostegard J, Ulfgren AK, Nyberg P, Hedin U, Swedenborg J, Andersson U, et al. Cytokine expression in advanced human atherosclerotic plaques: dominance of pro-inflammatory (Th1) and macrophage stimulating cytokines. Atherosclerosis 1999;145(1): 33-43.

34. Castagna O, Boussuges A, Nussbaum E, Marqueste L, Brisswalter J. Peripheral arterial disease: an underestimated aetiology of exercise intolerance in chronic obstructive pulmonary disease patients. Eur J Cardiovasc Prev Rehabil 2008;15(3):270-277. 